Erratum

\title{
Dynamic study of a field emission sensor based on carbon nanotubes for acceleration and high frequency vibration sensing
}

A. Malekan, Y. Abdi, and E. Arzi ${ }^{\mathrm{a}}$

Nano-Physics Research Laboratory, Department of Physics, University of Tehran, Tehran, Iran

Accepted: 5 September 2011

Published online: 28 September 2011 - (C) EDP Sciences 2011

Eur. Phys. J. Appl. Phys. 55, 10403 (2011), DOI: 10.1051/epjap/2011110013

An error occurred during the publication process in the Aims and Scopes sections of the contents: This article should be under section Nanomaterials and Nanotechnologies.

We apologize for this inconvenience.

a e-mail: arzi@khayam.ut.ac.ir 